\title{
METODOLOGIA DE INOCULAÇÃO E PARÂMETROS DE AVALIAÇÃO DA MANCHA PARDA DO ARROZ CAUSADA POR
}

Helminthosporium oryzae

\section{NELSON SIDNEI MASSOLA JÚNIOR}

Engenheiro Agrônomo

Orientador: Prof. Dr. IVAN PAULO BEDENDO

Dissertação apresentada à Escola Superior de Agricultura 'Luiz de Queiroz", da Universidade de São Paulo, para obtenção do título de Mestre em Agronomia, Área de concentração: Fitopatologia.

P I R A C I C A B A

Estado de São Paulo - Brasil

Novembro - 1994 


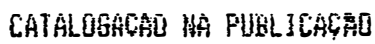

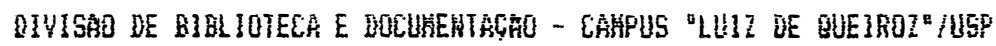

Ma550la Jünior, helson Sidné

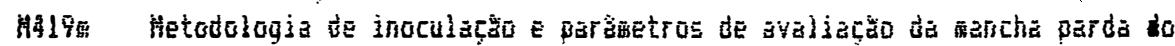
arroz causada for helejothosuoriud of viate. Firacicaba. 1994.

43ß. ilus.

Bise. (HEstre) - ESALE

Bibliogratis.

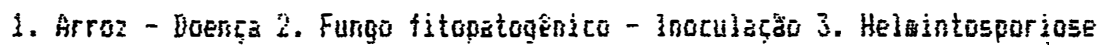
do arroz 4. Hancha parda da arroz 1. Escoia Superior de foricultura Luiz de Queiraz, Firacicaba

CoI $\frac{1}{3} 3.18$ 


\section{METODOLOGIA DE INOCULAÇĀO E PARÂMETROS DE AVALIAÇĀO DA MANCHA PARDA DO ARROZ CAUSADA POR \\ Helminthosporium oryzae}

NELSON SIDNEI MASSOLA JÚNIOR

Aprovada em: 23.11.1994

Comissão julgadora:

Prof. Dr. Ivan Paulo Bedendo

ESALQ/USP

Prof. Dr. Tasso Leo Krügner

ESALQ/USP

Dr. Jaciro Soave

IAC/Campinas

4

cuarpedendo

Prof. Dr. Ivan Paulo Bedendo Orientador 


\section{AGRADECIMENTOS}

$\mathrm{O}$ autor agradece à todos aqueles que, de alguma forma, contribuíram para a realização deste trabalho, em especial

- Ao Prof. Dr. Ivan Paulo Bedendo, pelas sugestões, orientação e companheirismo demonstrados durante o curso.

- À todos os professores, funcionários e alunos do Departamento de Fitopatologia da Escola Superior de Agricultura "Luiz de Queiroz", pelos ensinamentos e amigável convivência.

- À Coordenação de Aperfeiçoamento de Pessoal de Nível Superior - CAPES, pela bolsa de estudo concedida.

- Aos engenheiros agrônomos José Renato Stangarlin e Everaldo Peccinin e à farmacêutica Márcia Cristina Roncatto, pelo auxílio nas inoculações.

- Aos Drs. Anne Sitarama Prabhu, Alceu Sallaberry Ribeiro e Jaciro Soave, pelo fornecimento dos isolados e sementes de arroz.

- Ao engenheiro agrônomo Carlos Eduardo Pulcinelli, pelas valiosas sugestões e auxílio nas avaliações.

- Ao amigo Vítor Hugo Artigiani, pelas orientações nas análises estatísticas.

- Ao Prof. Dr. Tasso Leo Krügner, pela confecção do Summary.

- Aos funcionários da Divisão de Biblioteca e Documentação, especialmente à Eliana Maria Garcia Sabino e Kátia Maria Andrade Ferraz, pela correção das referências bibliográficas e amizade demonstrada. 
À minha família

ofereço 


\section{SUMÁRIO}

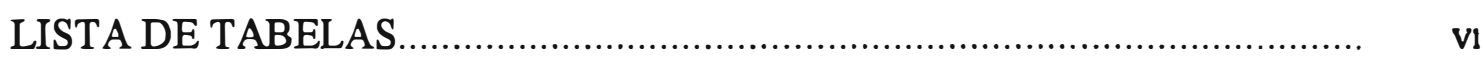

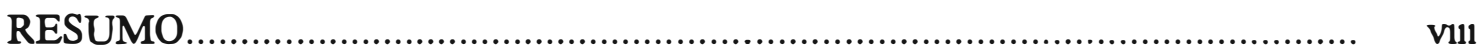

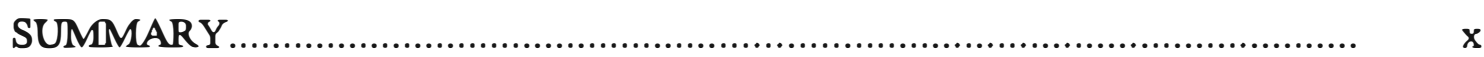

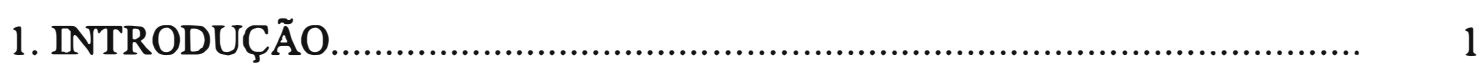

2. REVISÃO DE LITERATURA................................................................ 3

3. MATERIAL E MÉTODOS....................................................................

3.1. Variedades de arroz utilizadas...............................................................

3.2. Isolados de $\mathrm{H}$. oryzae utilizados.............................................................

3.3. Ensaio conduzido em casa de vegetação.................................................. 10

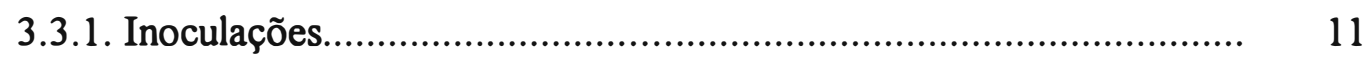

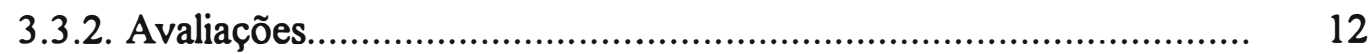

3.4. Ensaio conduzido com folhas destacadas em placas de Petri..................... $\quad 14$

3.4.1. Inoculações............................................................................ 15

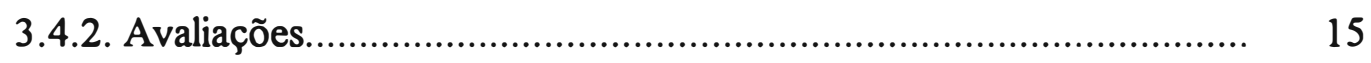

3.5. Ensaio conduzido em câmara de crescimento........................................... 15

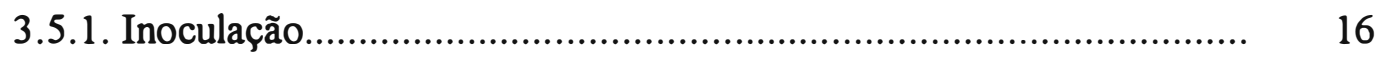

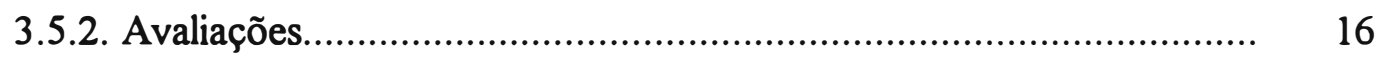

3.6. Ensaio conduzido no campo................................................................ 16

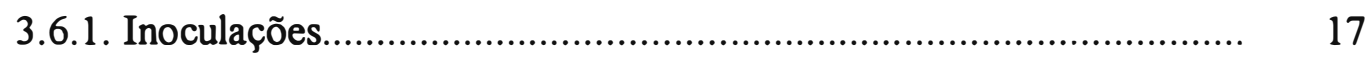

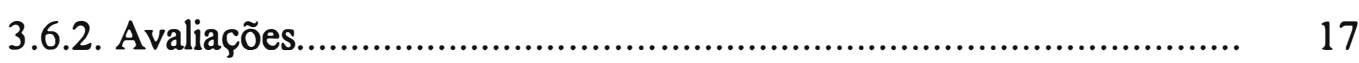

4. RESULTADOS E DISCUSSÃO_.............................................................. 19

4.1. Ensaio conduzido em casa de vegetação................................................... 19

4.2. Ensaio conduzido com folhas destacadas em placas de Petri..................... 25

4.3. Ensaio conduzido em câmara de crescimento............................................. 31

4.4. Ensaio conduzido no campo................................................................ 31

4.5. Relação entre os ensaios.................................................................... 34

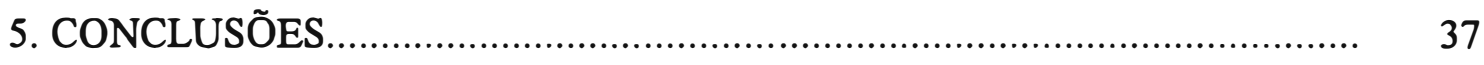

REFERÊNCIAS BIBLIOGRÁFICAS............................................................ 38 


\section{LISTA DE TABELAS}

Tabela 1. Procedência das variedades de arroz utilizadas nos ensaios.

Tabela 2. Reações de variedades de arroz inoculadas com suspensão de conídios do isolado H.O. 82-1 em casa de vegetação

Tabela 3. Reações de variedades de arroz inoculadas com suspensão de conídios do isolado $\mathrm{H} 22$ em casa de vegetação

Tabela 4. Reações de variedades de arroz inoculadas com suspensão de micélio do isolado H.O. 82-1 em casa de vegetação.

Tabela 5. Reações de variedades de arroz inoculadas com suspensão de conídios e de micélio do isolado H.O. 82-1 em casa de vegetação......

Tabela 6. Reações de variedades de arroz inoculadas com suspensão de conídios do isolado H.O. 82-1 em placas de Petri.

Tabela 7. Reações de variedades de arroz inoculadas com suspensão de conídios do isolado $\mathrm{H} 22$ em placas de Petri.

Tabela 8. Reações de variedades de arroz inoculadas com suspensão de micélio do isolado H.O. 82-1 em placas de Petri

Tabela 9 Área das lesões em 16 variedades de arroz inoculadas através de discos de micélio do isolado H.O. 82-1 em placas de Petri. 
Tabela 10 Reações de variedades de arroz inoculadas com suspensões de conídios e de micélio do isolado H.O. 82-1 em placas de Petri.

Tabela 11. Índice de doença em panículas de 4 variedades de arroz inoculadas por injeção de suspensões de inóculo no campo.

Tabela 12. Porcentagem de perda de peso dos grãos, em relação à testemunha inoculada com água, para 4 variedades inoculadas através de injeção de suspensões de inóculo no campo

Tabela 13. Reações de 4 variedades de arroz inoculadas com suspensão de conídios do isolado H.O. 82-1 casa de vegetação e no campo............. 


\title{
METODOLOGIA DE INOCULAÇÃO E PARÂMETROS DE AVALIAÇÃO DA MANCHA PARDA DO ARROZ CAUSADA POR \\ Helminthosporium oryzae.
}

\author{
Autor : Nelson Sidnei Massola Júnior \\ Orientador : Prof. Dr. Ivan Paulo Bedendo
}

\section{RESUMO}

No presente trabalho, foram estudadas diferentes metodologias de inoculação e parâmetros de avaliação da mancha parda do arroz, tomando por base a reação exibida por algumas variedades. Dezesseis variedades de arroz foram inoculadas com dois isolados de $H$. oryzae sob condições de casa de vegetação, câmara de crescimento, placas de Petri e campo.

Os resultados dos ensaıs demonstraram que apenas as inoculações com suspensão de conídios do isolado mais patogênico permitiu caracterizar adequadamente a reação de cada variedade. Inoculações com micélio do isolado mais patogênico e com micélio e conídios do isolado menos patogênico não permitiram que fossem detectadas variações significativas quanto às reações das variedades, avaliadas através de diversos parâmetros.

As reações varietais obtidas em casa de vegetação não se relacionaram com aquelas obtidas em placas de Petri e em câmara de crescimento. Porém, os resultados provenientes do ensaio no campo mostraram estreita relação com os de casa de vegetação, mais especificamente entre os parâmetros que medem a resistência à colonização, como por exemplo o tipo e a área das lesões.

Desse modo, sugere-se a possibilidade de se avaliar a resistência de materiais de arroz empregando-se plantas mantidas em casa de vegetação e tomando-se por base as reações foliares exibidas pelas mesmas. Entretanto, é necessário que o isolado utilizado 
apresente alta patogenicidade e que se avaliem as reações através de parâmetros que representem a resistência à colonização 


\section{METHODOLOGY OF INOCULATION AND PARAMETERS OF EVALUATION OF BROWN SPOT OF RICE CAUSED BY \\ Helminthosporium oryzae}

Author : Nelson Sidnei Massola Júnior

Adviser : Prof. Dr. Ivan Paulo Bedendo

\section{SUMMARY}

Different methodologies of inoculation and parameters of evaluation of rice brown spot were studied, based on the reaction of some varieties. Sixteen rice varieties were inoculated with two isolates of $H$. oryzae under greenhouse, growth chamber, Petri dish and field conditions.

The results showed that only the inoculations with a conidial suspension of the most pathogenic isolate made possible the adequate characterization of the reaction of each variety. Inoculations with mycelium of the most pathogenic isolate and with mycelium and conidia of the less pathogenic isolate did not allow for the detection of significant variations among varieties evaluated through some parameters.

The varietal reactions obtained in greenhouse were not related to those obtained in Petri dishes and growth chamber. However, the field results showed close relationship with those of greenhouse, more specifically among parameters that measure resistance against colonization, such as type and area of lesions.

Therefore, it is suggested the possibility of resistance evaluation of rice materials by employing plants kept in the greenhouse based on the reaction of their leaves. It is, however, necessary that the isolate employed have high pathogenicity and the reactions evaluated through parameters that indicate resistance against colonization. 


\section{INTRODUÇÃO}

O arroz é uma cultura tradicional em muitos países, inclusive no Brasil, servindo como alimento básico para o homem, além de ser usado na extração de óleos comestíveis. Além disso, o farelo de arroz, um subproduto do beneficiamento, pode ser utilizado na composição de rações para alimentação animal, constituindo importante fonte de proteína vegetal. Entretanto, a produção de arroz é bastante limitada por uma série de fatores, entre os quais pode-se destacar os de caráter fitopatológico.

Entre as várias doenças que atacam 0 arroz, a mancha parda ou helmintosporiose, causada pelo fungo Helminthosporium oryzae (Breda de Haan), ocupa o segundo lugar em importância econômica na maioria dos países produtores, sendo superada somente pela brusone (OU, 1985).

A doença ocorre tanto em culturas de sequeiro como irrigadas, sendo que as cultivares plantadas em sistema irrigado têm se mostrado mais suscetíveis em relação às cultivares de sequeiro.

Os sintomas podem se manifestar desde as fases iniciais da cultura, causando queima de plântulas originadas de sementes infectadas. Entretanto, em condições de campo, é mais comum o aparecimento da doença no final do ciclo, quando causa infecção nos grãos e reduz a produção devido ao "chocheamento", perda de peso e gessamento.Os grãos infectados apresentam manchas de coloração marrom escuro, que podem ocasionalmente cobrir o grão inteiro (PRABHU \& BEDENDO, 1982a) 
Entre os métodos de controle de doenças, o uso de variedades resistentes é muito enfatizado e, em muitos casos, torna-se a única alternativa viável. No Brasil, esse método é particularmente importante no controle da brusone, sendo que todo o programa de melhoramento varietal de arroz no país é desenvolvido principalmente em função dessa doença. A resistência das variedades em relação às demais doenças fica em segundo plano, como pode ser observado no trabalho realizado por GUIMARÃES et al. (1989). Devido a essa falha na avaliação de variedades, corre-se o risco de se lançar um material que seja muito suscetível a uma determinada doença, o que acarretaria enormes prejuízos na ocorrência de uma epidemia.

Esse trabalho de pesquisa teve por objetivo testar diferentes métodos de inoculação e parâmetros de avaliação, visando a obtenção de um método prático para avaliação da reação varietal de arroz à mancha parda. 


\section{REVISÃO DE LITERATURA}

A mancha parda do arroz está distribuída pelo mundo todo e tem sido relatada causando danos em todos os países que cultivam o arroz (OU, 1985).

As perdas associadas a essa doença estão relacionadas, principalmente, com a infecção nos grãos, como relataram PADMANABHAN et al. (1948). Contudo, os danos causados pela doença não se restringem somente à perda de peso dos grãos infectados, mas também à redução na germinação e queima de plântulas originadas de sementes infectadas (BEDI \& GILL, 1960).

Nos grãos, os prejuízos são maiores quando a infecção ocorre nos estádios ınıciaıs. FAZLI \& SCHROEDER (1966a), constataram uma relação inversa entre precocidade da infecção e produção de grãos em plantas de arroz inoculadas artificialmente nas panículas. Desse modo, os autores encontraram redução de $23 \%$ e $8 \%$ quando inocularam as panículas nas fases de floração e maturação, respectivamente.

No Brasil, devido à grande severidade da brusone, existem poucos dados relativos às perdas causadas por $H$. oryzae. Entretanto, PRABHU et al. (1980), trabalhando com seis cultivares de sequeiro no Pará, encontraram redução na produção de até $30 \%$ devido à mancha parda. Assim como no trabalho de PADMANABHAN et al. (1948), essa redução esteve associada à infecção nos grãos, com exceção das variedades CICA-4 e "Canela-de-ferro", onde a infecção nas folhas contribuiu significativamente para a variação. 
$\mathrm{O}$ agente causal, $H$. oryzae é um fungo imperfeito da ordem Moniliales. Sua fase perfeita corresponde a Cochliobolus miyabeanus (Ito \& Kuribayashi), ainda não relatada no Brasil. A principal fonte de inóculo da doença é representada pelas sementes contaminadas, através das quais o patógeno é disseminado entre os campos de produção ou sobrevive de uma estação para outra (PADMANABHAN et al., 1953). Além disso, há estudos que evidenciam, a capacidade do fungo de infectar outras gramineas cultivadas, as quais podem atuar como hospedeiros alternativos (NELSON \& KLINE, 1961 e ARTIGIANI FILHO \& BEDENDO, 1994).

O controle químico da mancha parda, tanto através do tratamento de sementes como de pulverizações foliares, é uma medida que vem sendo pesquisada por diversos autores. BRIGNANI NETO et al. (1979) verificaram que o tratamento de sementes de arroz com diversos fungicidas protegeram as plântulas apenas nas fases iniciais, não garantindo sua sobrevivência 30 dias após a semeadura. Resultados semelhantes a esses foram obtidos por VALARINI et al. (1988), que não observaram aumento nos parâmetros emergência e produção de grãos através do tratamento de um lote de sementes que apresentava $46 \%$ de infecção por $H$. oryzae. Esses dados demonstram que o tratamento de sementes, apesar de econômico, apresenta eficiência satisfatória somente nas fases iniciais. Por outro lado, o controle através de pulverizações foliares tem mostrado bons resultados com alguns produtos, destacando-se o chlorothalonil e o propiconazole, como constataram BRIGNANI NETO et al. (1982) e FANTIN et al. (1994). Contudo, apesar de eficiente, esse método é economicamente inviável em nossas condições. Assim, no Brasil, deve-se enfatizar o emprego de variedades resistentes, considerado por OU (1985) o método mais eficiente e econômico de controle.

Trabalhos de avaliação da reação varietal, com o objetivo de revelar fontes de resistência, têm sido realizados em diversas partes do mundo, tanto a nível de campo 
como em condições controladas. No Brasil, a maioria das pesquisas desenvolvidas nessa linha visam obter fontes de resistência para a brusone, embora existam alguns trabalhos sobre mancha parda.

Há, porém, uma certa lacuna quanto à existência de uma metodologia padronizada para inoculação e avaliação que permita reconhecer de forma prática e segura a reação varietal à mancha parda, quando se busca identificar materiais que possam atuar como fontes de resistência. Dessa forma, muitos autores utilizam a metodologia dos infectários naturais (OU, 1985) desenvolvida para brusone (SRIVASTAVA \& MAHESHWARI, 1971; SINGH \& SHARMA, 1975; RIBEIRO, 1977; SOUSA et al., 1986 e SINGH, 1988), enquanto outros utilizam as infecções naturais a nível de campo (ISSA et al., 1973; PRABHU et al., 1986 e SANTOS \& GALVÃO, 1989) para determinar a reação das variedades.

Uma outra técnica comumente empregada é a de inoculação sob condições controladas. As plantas de arroz são mantidas em casa de vegetação e submetidas a inoculações com suspensão padronizada de conídios, em idades variadas. Após a inoculação, costuma-se deixar as plantas em câmara úmida por períodos que variam de 24 a 72 horas. Normalmente a avaliação é feita de 7 a 10 dias após a inoculação (ISLA, 1978; BEDENDO \& PRABU, 1979; LAKSHMANAN \& VELUSAMY, 1991 e MALAVOLTA et al., 1992). Em comparação com os dois métodos anteriormente mencionados, este apresenta uma série de vantagens, como melhor controle do ambiente, economia de espaço e tempo, independência dos fatores climáticos e melhor distribuição do inóculo. Porém, este método falha em considerar a reação da variedade com base apenas na infecção foliar, uma vez que os maiores danos causados pela doença provém da infecção nos grãos. Além disso, a resistência a $H$. oryzae depende da idade da planta. Diversos autores têm demonstrado um aumento na suscetibilidade do arroz à mancha 
parda a medida que a planta fica mals velha (SHERF et al., 1947; FAZLI \& SCHROEDER, 1966a e ASHOUR et al., 1973).

Além dessas, diversas outras formas para avaliação de variedades têm sido criadas ou adaptadas para o arroz. GANGULY \& PADMANABHAN (1959) e PADMANABHAN et al. (1965) avaliaram cerca de 1000 variedades de arroz cultivadas na Índia através de uma combinação de métodos, nos sucessivos estádios de desenvolvimento da cultura. Inicialmente, as plântulas de todas as variedades foram submetidas a inoculações artificiais em casa de vegetação. Numa segunda fase, as variedades foram expostas à infecção natural no campo, onde foram avaliadas durante todos os estádios de crescimento. Somente aquelas que se comportaram como resistentes nesses dois ensaios prosseguiram na avaliação e foram incluídas na série final de testes, através de infecção artificial no campo. De todas as variedades testadas, os autores selecionaram apenas 10 como resistentes através dessa técnica.

FARIA \& PRABHU (1980) desenvolveram uma técnica para avaliar a resistência de variedades de arroz a Rhyncosporium oryzae. O método consiste em depositar sobre a folha um disco de micélio retirado de uma colônia cultivada em meio BDA. A reação da variedade é avaliada pelo comprimento da lesão formada após um período de incubação. A mesma técnica foi posteriormente utilizada em diversas gramíneas por PRABHU \& BEDENDO (1982b) e novamente em arroz por PRABHU \& BEDENDO (1990). Mais recentemente, BROERS \& LOPEZ-ATILANO (1994) empregaram uma modificação desse método para medir componentes de resistência do trigo a Puccinia striiformis.

A infecção nos grãos, tanto natural quanto provocada artificialmente também pode ser utilizada para determinar a reação varietal. A frequência de infecção dos grãos por alguns patógenos, entre os quais $H$. oryzae, é um bom indicador do comportamento 
da variedade, uma vez que há correlação direta entre a porcentagem de infecção e perda de peso dos grãos. Desse modo, um teste de sanidade de sementes pode ser um instrumento útil num processo de seleção de variedades (SOAVE et al., 1984).

Infeç̧ão artificial das panículas pode ser conseguida por meio de pulverização das mesmas com uma suspensão de conídios (FAZLI \& SCHROEDER, 1966b) ou através da técnica desenvolvida por BEDENDO \& PRABHU (1982). Esses autores conseguiram selecionar variedades de arroz resistentes à mancha parda nos grãos inoculando a panícula ainda no interior da bainha das plantas, 2 a 3 dias antes da emissão das mesmas, através da injeção de uma suspensão de conídios. $\mathrm{O}$ método se mostrou eficiente e prático, permitindo que se comparasse um grande número de cultivares sob as mesmas condições de infecção. Posteriormente, POPE \& McCARTER (1992) compararam diversos métodos de inoculação para induzir a formação do carvão da espiga, em milho. A inoculação através da suspensão de esporos foi sempre o método que proporcionou as maiores incidências e severidades da doença.

O tipo de inóculo também tem sido estudado por alguns pesquisadores, visando solucionar basicamente o problema da dificil esporulação de alguns patógenos. Para Helminthosporium oryzae, SHERF et al. (1947) e GANGULY \& PADMANABHAN (1959) determinaram que fragmentos secos de micélio são capazes de causar infeç̧ão quando polvilhados sobre folhas de arroz previamente umidecidas. Apesar da infecção por fragmentos de micélio ter sido idêntica à causada por conídios, foi necessária uma quantidade bem maior de micélio por unidade de área para causar o mesmo nível de infecção.

Atualmente, percebe-se um aumento na procura por técnicas de inoculação que proporcionem eficiência, praticidade e economia de espaço e tempo. A técnica de bioensaio através de folhas destacadas combina todas essas vantagens. $\mathrm{O}$ método, descrito 
na revisão feita por YARWOOD (1956), consiste em manter folhas, ou parte delas, em placas de Petri contendo uma camada de algodão coberta com papel de filtro umedecido. Nessa condições, as folhas permanecem vivas por alguns dias, permitindo a condução dos ensaios. Folhas de algumas culturas, como amendoim e feijão, apresentam a capacidade de enraizar nas placas, permanecendo vivas por muito mais tempo (MORAES \& SALGADO, 1982 e MENDES \& BERGAMIN FILHO, 1986).

Essa técnica vem sendo utilizada em diversas dicotiledôneas para estudos envolvendo as relações patógeno-hospedeiro, tais como quantificação de parâmetros epidemiológicos, determinação da reação varietal e até mesmo em controle químico (WARD, 1959; MORAES \& SALGADO, 1982; MENDES \& BERGAMIN FILHO, 1986 e BEDENDO \& KRÜGNER, 1987). Porém, existem poucos estudos utilizando a técnica da folha destacada em monocotiledôneas devido ao tamanho e a forma das folhas. Entretanto, WILCOXSON et al. (1974) avaliaram a reação de diversas variedades de trigo à ferrugem através dessa técnica, encontrando boa correlação com os resultados obtidos no campo. 


\section{MATERIAL E MÉTODOS}

Os trabalhos foram desenvolvidos no Departamento de Fitopatologia da Escola Superior de Agricultura "Luiz de Queiroz" - Universidade de São Paulo, em Piracicaba, São Paulo, no período compreendido entre agosto de 1992 e julho de 1994.

\subsection{Variedades de arroz utilizadas}

Dezesseis variedades de arroz, escolhidas com base em informações da literatura e em testes preliminares, foram utilizadas nos ensaios. As procedências dessas variedades são mostradas na Tabela 1.

\subsection{Isolados de $\boldsymbol{H}$. oryzae utilizados}

Um total de 12 isolados de H. oryzae provenientes do IAC - Campinas, IRGA Pelotas, e CNPAF/EMBRAPA - Goiânia, foram submetidos a um teste de esporulação em meio $\mathrm{BDA}+1 \%$ de peptona, que tem se mostrado favorável à esporulação desse fungo. Sete isolados se mostraram esporulantes nessas condições, os quais foram inoculados em plantas de arroz mantidas em casa de vegetação, para verificação da patogenicidade. Dois isolados se destacaram pela severidade de doença que proporcionaram: o isolado H.O. 82-1 (CNPAF/EMBRAPA) e o isolado H 22 (IRGA). Tais isolados foram recuperados das plantas inoculadas através de isolamento feito a partir de lesões típicas. Em seguida foram repicados para tubos de ensaio contendo meio BDA e armazenados em refrigerador para posterior utilização nos ensaios. 
Tabela 1. Pocedência das variedades de arroz utilizadas nos ensaios.

\begin{tabular}{ll}
\hline Variedades & Procedência \\
\hline IAC 201 & IAC - Campinas \\
Awini & IRGA - Pelotas \\
Agulha Bico Torto & IRGA - Pelotas \\
Caloro & IRGA - Pelotas \\
Dular & IRGA - Pelotas \\
IV - $29-4$ & IRGA - Pelotas \\
Dawn & EMBRAPA - Goiânia \\
Labelle & EMBRAPA - Goânia \\
Lebonet & EMBRAPA - Goiânia \\
IR - 8 & EMBRAPA - Goiânia \\
IR - 5 & EMBRAPA - Goiânia \\
Cica - 8 & EMBRAPA - Goiânia \\
Metica - 1 & EMBRAPA - Goiânia \\
Carreon & EMBRAPA - Goiânia \\
Colômbia - 1 & EMBRAPA - Goiânia \\
Taichung & EMBRAPA - Goiânia \\
\hline
\end{tabular}

\subsection{Ensaio conduzido em casa de vegetação}

Este teste foi conduzido com o objetivo de se verificar a reação de cada variedade em condições de casa de vegetação, com a finalidade de se eleger um método adequado para inoculação e avaliação nessas condições.

Cada variedade foi plantada em vasos de alúminio (3 plantas/vaso) contendo solo esterilizado (mistura, em partes iguais, de areia, solo argiloso e esterco de curral). Os vasos permaneceram em casa de vegetação e foram regados diariamente, até que as plantas completassem 30 dias após a emergência, quando se procederam às inoculações. 


\subsubsection{Inoculações}

Nesse ensaio, cada variedade de arroz foi inoculada através de 4 métodos para cada isolado do fungo, como descrito abaixo:

Pulverização de suspensão de conídios: Colônias do fungo crescidas em BDA $+1 \%$ de peptona foram raspadas, superficialmente, em água destilada esterilizada para obtenção de uma suspensão, que foi filtrada em gase para separação dos fragmentos de micélio. Essa suspensão teve sua concentração calibrada em cerca de $10^{4}$ conídios $/ \mathrm{ml}$ com o auxílio de um hemacitômetro. Em seguida foi pulverizada sobre as plantas de arroz até o ponto de escorrimento.

Pulverização de suspensão de micélio: Micélio livre de conídios foi obtido através de uma modificação na metodologia descrita por SHERF et al. (1947). Ambos os isolados do fungo foram repicados para frascos erlenmeyers de $250 \mathrm{ml}$ contendo $100 \mathrm{ml}$ de meio líquido batata-dextrose. Os frascos permaneceram sob constante agitação por cinco dias. Após esse período, o conteúdo dos frascos foi filtrado e o micélio retido foi seco em papel de filtro. Pedaços de micélio foram fragmentados em água esterilizada através de um mixer SORVALL a $3000 \mathrm{rpm}$ durante um minuto, na proporção de 1 grama de micélio para $1000 \mathrm{ml}$ de água. A suspensão resultante foi filtrada em gase e pulverizada sobre as plantas de arroz até o ponto de escorrimento.

Deposição de papel de filtro embebido em suspensão de conídios: Para essa metodologia de inoculação, discos de papel de filtro com $5 \mathrm{~mm}$ de diâmetro foram embebidos numa suspensão de conídios contendo cerca de $10^{4}$ conídios/ml e depositados na face superior das folhas de cada variedade de arroz. Um total de 10 folhas de cada vaso foram inoculadas dessa forma.

Deposição de disco de micélio: Discos de micélio com $3 \mathrm{~mm}$ de diâmetro foram retirados de colônias de ambos os isolados cultivados 5 dias em BDA. Tais discos foram 
depositados sobre a superficie superior das folhas de cada variedade, num total de 10 folhas para cada vaso.

Nas inoculações por pulverização de suspensão de conídios ou micélio, utilizouse um pulverizador manual com capacidade para $500 \mathrm{ml}$. Foi ainda acrescentada uma gota de Tween 20 para cada $100 \mathrm{ml}$ de suspensão. Cada vaso contendo 3 plantas foi considerado como uma repetição, sendo que foram utilizadas três repetições para cada combinação entre variedade, isolado e forma de inoculação.

Após a inoculação, os vasos permaneceram no interior de uma câmara úmida com nebulizador constantemente ligado. A temperatura foi controlada para permanecer entre $25^{\circ} \mathrm{C}$ e $30^{\circ} \mathrm{C}$ que, segundo SHERF et al. (1947), é a faixa ideal para ocorrência de infecções. O regime de luz utilizado foi de 12 horas de luz e 12 horas de escuro, conseguido através de um "timer" acoplado a uma série de lâmpadas fluorescentes. Após a inoculação, as plantas foram mantidas por 48 horas em câmara úmida e, posteriormente, permaneceram por um período de oito dias em casa de vegetação, ao término do qual foram realizadas as avaliações.

\subsubsection{Avaliações}

As avaliações foram realizadas dez dias após a inoculação. Nas inoculações através de pulverizações de suspensão de conídios e micélio, a reação de cada variedade foi avaliada através dos parâmetros tipo de lesão, número de lesões por centímetro, número de lesões por folha e área das lesões. A área foi obtida multiplicando-se o comprimento pela largura da lesão. Além disso, a cada variedade foi atribuída uma nota de 1 a 6, segundo a escala de ALUKO (1970), reproduzida a seguir: 
Altamente resistente : Folhas com pequenos pontos escuros, menores que $0,5 \mathrm{~mm}$. Sem centro necrótico.

Resistente : Folhas com pontos marrons grandes, de 0,5 a 1,0 mm de diâmetro. Sem centro necrótico.

Moderadamente resistente : Folhas apresentando manchas com centro necrótico pequeno e arredondado, por volta de $1,0 \mathrm{~mm}$ de diâmetro, circundado por uma margem marrom.

Moderadamente suscetivel : Folhas apresentando lesões típicas da mancha parda, circulares ou ovais, de 1,0 a 4,0 mm de diâmetro, com um grande centro necrótico e margem marrom ou avermelhada. Em geral, relativamente poucas sobre as folhas (menos que 50 por folha).

Suscetível : Numerosas lesões (50 a 100) como as do grupo 4 ou frequentemente maiores por folha. Uma pequena porção de área foliar (menos que 25\%) pode ser morta por coalescência de lesões.

Muito suscetível : Folhas com lesões grandes e de expansão rápida, por volta de $5 \mathrm{~mm}$ de comprimento e em maior número que no grupo 5. Extensão foliar morta por coalescência ultrapassa $25 \%$ da área foliar. 
O tipo de lesão foi atribuído de acordo com uma escala descritiva, reproduzida abaixo :

\section{Tipo de lesão Reação $\quad$ Descrição}

A

Resistente Lesões pequenas, arredondadas ou alongadas, marrom avermelhadas, sem centro necrótico.

B

Intermediária

Lesões alongadas, com centro necrótico pequeno (cerca de $1 \mathrm{~mm}$ de diâmetro), circundado por bordo marrom avermelhado.

C

Suscetível

Lesões alongadas, com centro necrótico grande (maior que $1 \mathrm{~mm}$ ) e de expansão rápida.

Quando a inoculação foi através da deposição de disco de papel de filtro ou micélio, a avaliação foi realizada através da área da lesão formada, obtida de maneira já descrita.

\subsection{Ensaio conduzido com folhas destacadas em placas de Petri}

Plantas de cada variedade foram mantidas em vasos contendo solo esterilizado até completarem 30 dias após a emergência, sob condições de casa de vegetação. Após esse período, as plantas foram levadas ao laboratório, onde as folhas completamente expandidas foram destacadas. Um segmento de $7 \mathrm{~cm}$ do terço médio de cada folha foi transferido para uma placa de Petri contendo uma fina camada de algodão coberta com papel de filtro embebido em água esterilizada. A extremidade anterior de cada segmento 
foi envolvida em algodão molhado, para evitar desidratação. Em cada placa foram colocados de 3 a 4 segmentos de folha, sendo que uma lâmina de vidro os manteve isolados do papel de filtro.

\subsubsection{Inoculações}

Os segmentos de folha de arroz foram inoculados através de pulverizações de suspensão de conídios e micélio, e também através da deposição de discos de micélio. A obtenção das suspensões e dos discos de micélio foi idêntica à descrita na fase anterior. A pulverização das suspensões foi feita através de um pulverizador manual DeVilbiss no 15. Após as inoculações, as placas foram fechadas, recebendo uma folha de plástico tansparente sob a tampa para manter elevada a umidade no interior das mesmas (MORAES \& SALGADO, 1982). As placas assim montadas permaneceram em bancada de laboratório sob condições ambientes durante 7 dias . Após 48 horas da inoculação, as folhas de plástico foram retiradas.

\subsubsection{Avaliações}

Foram realizadas três avaliações em diferentes períodos, ou seja, no $3^{\circ}, 5^{\circ}$ e $7^{\circ}$ dias após a inoculação. Os parâmetros avaliados foram tipo, área e número de lesões por segmento de folha, quando a inoculação foi através de pulverização de suspensão. Também atribuiu-se, para cada variedade, uma nota segundo a escala de Aluko, já mencionada. Quando a inoculação foi através da deposição de disco de micélio, mediu-se a área da lesão formada.

\subsection{Ensaio conduzido em câmara de crescimento}

Devido à dificuldade na inoculação através da deposição de disco de micélio, verificada no teste em casa de vegetação, instalou-se esse experimento em câmaras de crescimento CONVIRON. Quatro plantas de cada variedade foram plantadas em vasos 
contendo solo esterilizado e mantidas em uma câmara de crescimento regulada para $28^{\circ} \mathrm{C}$ e fotoperíodo de 12 horas de luz e 12 horas de escuro até completarem 45 dias após a emergência. Nessa idade, as folhas completamente expandidas foram fixadas com fita adesiva a um suporte de papel cartão acoplado ao vaso, para facilitar a inoculação.

\subsubsection{Inoculação}

Um disco de micélio de $3 \mathrm{~mm}$ de diâmetro do isolado H.O. 82-1, proveniente de uma cultura de 5 dias em BDA, foi depositado no centro de cada folha. Em cada vaso inocularam-se de 15 a 20 folhas, com exceção das variedades Dawn e Lebonet, que não se desenvolveram satisfatoriamente na câmara de crescimento e não foram usadas nesse ensaio. Para manter a umidade elevada, um saco plástico umidecido foi colocado sobre cada vaso, o qual foi retirado 48 horas após a inoculação.

\subsubsection{Avalią̧ões}

As avaliações foram realizadas diariamente, do $4^{\circ}$ ao $T^{\circ}$ dia após a inoculação, através do parâmetro área das lesões coalescidas.

\subsection{Ensaio conduzido no campo}

As variedades foram semeadas no campo no dia 18 de novembro de $1993 \mathrm{em}$ três blocos, cada um constituído por 16 linhas de $2 \mathrm{~m}$, espaçadas $0,5 \mathrm{~m}$ entre si. Em cada linha foi plantada uma variedade, num delineamento casualizado. Cada bloco tinha ainda 2 linhas de bordadura da variedade IAC-201.

A adubação de plantio foi realizada com adubo de formulação 4-14-8, na proporção de $50 \mathrm{~g}$ de adubo para cada linha de $2 \mathrm{~m}$. Foram feitas ainda duas adubações de cobertura, em 15 de novembro de 1993 e em 06 de janeiro de 1994, com sulfato de amônio, na mesma proporção acima. A irrigação do experimento foi por aspersão, permanecendo ligada em média 30 minutos por dia. 


\subsubsection{Inoculações}

As inoculações foram realizadas quando as plantas estavam na fase de "emborrachamento", ou seja, alguns dias antes da emissão das panículas. A técnica utilizada foi a de injeção de suspensão de inóculo na bainha, descrita por BEDENDO \& PRABHU (1982), utilizando-se tanto suspensões de conídios como de micélio.

Suspensões contendo cerca de $10^{4}$ esporos/ml foram preparadas a partir de colônias de ambos os isolados cultivados 10 dias em BDA $+1 \%$ de peptona, de maneira já descrita. Tais suspensões foram diluídas até a concentração de 0,3 x $10^{3}$ esporos $/ \mathrm{ml}$ para a inoculação. Suspensões de micélio dos dois isolados, obtidas de maneira idêntica à descrita anteriormente, foram diluídas na mesma proporção. Um mililitro dessas suspensões foi injetado em cada bainha, com o auxílio de uma seringa. Para cada combinação entre variedade, isolado e tipo de suspensão foram inoculadas de 5 a 7 plantas escolhidas ao acaso em cada bloco, as quais receberam uma marcação para posterior identificação. Igual número de plantas de cada variedade recebeu $1 \mathrm{ml}$ de água estéril, servindo como testemunhas. Observou-se que as panículas inoculadas emergiram entre 2 a 3 dias após a inoculação. Cada variedade foi acompanhada até a fase de maturação, quando as panículas inoculadas foram retiradas e levadas ao laboratório para as avaliações.

\subsubsection{Avaliações}

Para avaliação da reação de cada variedade, os grãos foram retirados da panículas e agrupados segundo a escala abaixo:

Grão tipo 1 : ausência de manchas

Grão tipo 2 : presença de manchas isoladas ou até $25 \%$ do grão manchado.

Grão tipo 3 : de $25 \%$ a $50 \%$ do grão manchado.

Grão tipo 4 : mais que $50 \%$ do grão manchado. 
Para cada panícula avaliada, contou-se o número de grãos dos tipos 1, 2, 3 e 4 . Em seguida calculou-se o índice de doença (I D) com base na fórmula :

$$
\mathrm{ID}=\frac{\mathrm{A} .1+\mathrm{B} .2+\mathrm{C} .3+\mathrm{D} .4}{\mathrm{~A}+\mathrm{B}+\mathrm{C}+\mathrm{D}} \text {, onde : }
$$

$\mathrm{A}=$ número de grãos com nota 1

$\mathrm{B}=$ número de grãos com nota 2

$\mathrm{C}=$ número de grãos com nota 3

$\mathrm{D}=$ número de grãos com nota 4

Também avaliou-se a perda de peso dos grãos para cada combinação entre método de inoculação, isolado e variedade. Para isso, pesou-se 5 repetições de 100 grãos em cada uma dessas combinações e, em seguida, calculou-se a percentagem de perda de peso em relação à testemunha inoculada com água, através da fórmula :

$$
\% \text { Perda }=\frac{\text { Peso da testemunha }- \text { Peso do tratamento }}{\text { Peso da testemunha }} .100
$$




\section{RESULTADOS E DISCUSSÃO}

\subsection{Ensaio conduzido em casa de vegetação}

As plantas mantidas em casa de vegetação foram avaliadas dez dias após a inoculação, por ser esse o intervalo de tempo que permitiu melhor visualização das diferenças entre os métodos de inoculação, avaliados através das reações das variedades. Este intervalo foi determinado em ensaios conduzidos preliminarmente. Para todas as variedades testadas foi possível observar os primeiros sintomas da doença $\mathbf{4 8}$ horas após a inoculação, indicando que a infecção ocorreu dentro de um período de tempo relativamente curto. Esta constatação já havia sido relatada por SHERF et al. (1947), os quais demonstraram que um período de 10 horas de alta umidade relativa após a inoculação era suficiente para o estabelecimento da infecção.

As inoculações feitas através da deposição de discos de micélio ou de papel de filtro embebidos em suspensão de conídios, além do dispêndio de tempo exigido para a colocação dos discos na superficie das plantas, se mostraram inviáveis devido a baixa aderência dos mesmos à superficie das folhas de arroz. Estas dificuldades comprometeram o sucesso das inoculações e indicaram que essa metodologia não era adequada para inocular $H$. oryzae em plantas de arroz. Dessa forma, considerou-se apenas as inoculações realizadas através de pulverizações de suspensões de conídios e de micélio. 
A Tabela 2 apresenta os resultados da inoculação com suspensão de conídios do isolado H.O. 82-1. Os resultados mostraram que, para todos os parâmetros avaliados, foi possível classificar as variedades em resistentes, intermediárias e suscetíveis.

Tabela 2. Reações de variedades de arroz inoculadas com suspensão de conídios do isolado H.O. 82-1 em casa de vegetação.

\begin{tabular}{|c|c|c|c|c|c|c|c|c|}
\hline \multirow{2}{*}{$\begin{array}{l}\text { Variedade } \\
\text { CICA-8 }\end{array}$} & \multirow{2}{*}{$\begin{array}{c}\text { Tipo } \\
\text { lesão } \\
\text { A }\end{array}$} & \multirow{2}{*}{$\begin{array}{c}\text { Nota }^{(1)} \\
2 \\
\end{array}$} & \multicolumn{2}{|c|}{ No/cm } & \multicolumn{2}{|l|}{ No/follha } & \multicolumn{2}{|c|}{ Área $\left(\mathrm{mm}^{2}\right)$} \\
\hline & & & \multicolumn{2}{|c|}{$6,21 \mathrm{a}^{(2)}$} & \multicolumn{2}{|l|}{$180,33 \mathrm{a}$} & 0,36 & $\mathrm{e}$ \\
\hline IR-5 & A & 1 & \multicolumn{2}{|c|}{$6,05 \mathrm{a}$} & \multicolumn{2}{|c|}{$166,83 \mathrm{ab}$} & 0,25 & e \\
\hline Labelle & $\mathrm{A}$ & 2 & \multicolumn{2}{|c|}{$5,77 \mathrm{ab}$} & \multicolumn{2}{|l|}{193,16 a } & 1,31 & $\mathrm{~d}$ \\
\hline Lebonet & B & 3 & 4,33 & bc & 127,00 & & 1,77 & $d$ \\
\hline IAC-201 & B & 3 & 3,87 & cd & \multicolumn{2}{|c|}{$155,33 \mathrm{ab}$} & 1,22 & $d$ \\
\hline Metica-1 & B & 3 & 2,99 & cde & 80,33 & cde & 1,75 & $d$ \\
\hline Dawn & B & 3 & 2,94 & cde & 83,00 & cde & 1,79 & $d$ \\
\hline Carreon & $\mathrm{C}$ & 4 & 2,71 & def & 93,83 & $\mathrm{~cd}$ & 3,69 & b \\
\hline Colômbia-1 & $\mathrm{C}$ & 4 & 2,49 & defg & 73,33 & def & 3,37 & bc \\
\hline Taichung & B & 3 & 2,28 & efgh & 67,66 & def & 1,41 & $d$ \\
\hline IR-8 & B & 3 & 2,16 & efgh & 60,50 & def & 1,80 & $\mathrm{~d}$ \\
\hline Dular & B & 3 & 1,77 & efgh & 63,66 & def & 1,25 & $d$ \\
\hline IV-29-4 & $\mathrm{C}$ & 4 & 1,27 & fgh & 40,50 & ef & $6,62 \mathrm{a}$ & \\
\hline Ag. B. Torto & B & 3 & 1,11 & gh & 42,33 & ef & 1,52 & $d$ \\
\hline Caloro & $\mathrm{C}$ & 4 & 0,97 & gh & 33,33 & ef & 2,93 & c \\
\hline Awini & A & 1 & 0,90 & $\mathrm{~h}$ & 28,16 & $f$ & 0,25 & $\mathrm{e}$ \\
\hline
\end{tabular}

Médias de 10 repetiçôes. CV $=23,4 \%$

(1) Com base na escala de Aluko.,

(2) Médias seguidas por letras distintas, nas colunas, diferem entre si pelo teste de Tukey ao nivel de $5 \%$ de probabilidade.

Comparando-se a reação de cada uma das variedades, verifica-se uma correlação positiva entre os parâmetros tipo de lesão, nota e área das lesões. No entanto, as variedades CICA-8 e IR-5 que se comportaram como resistentes segundo estes parâmetros, por apresentarem lesões pequenas, se mostraram suscetíveis quando se 
considerou o número de lesões por centímetro e o número de lesões por folha. Por outro lado, a variedade IV-29-4, resistente segundo o parâmetro número de lesões por centímetro, apresenta lesões grandes, sendo classificada como suscetível quando se tomou por base a área das lesões.

Esta discrepância entre os resultados mencionados pode ser explicada, possivelmente, pelos mecanismos de resistência apresentados pelas variedades de arroz ao isolado do patógeno. Assim, pode-se inferir que as variedades CICA-8 e IR-5 apresentaram alta resistência à colonização e baixa resistência à infecção. Isso explica o fato dessas variedades terem apresentado um grande número de lesões, porém de tamanho pequeno. Para a variedade IV-29-4 ocorre o contrário, ou seja, o pequeno número de lesões reflete uma alta resistência à infecção e a grande área das lesões indica baixa resistência à colonização. Existem, porém, variedades que combinam estes dois tipos de resistência, como por exemplo a variedade Awini, que apresentou poucas lesões e de tamanho reduzido. Devido a estas características esse material pode se constituir em uma importante fonte de resistência para fins de melhoramento genético.

Quando as mesmas variedades foram inoculadas com o isolado $\mathrm{H}-22$, que se mostrou menos patogênico que o H.O. 82-1 nos testes para seleção dos isolados, não foi possível observar diferenças significativas nas reações varietais através dos parâmetros tipo de lesão, nota e área das lesões. Assim todas as variedades foram classificadas como resistentes segundo estes parâmetros (Tabela 3). Entretanto, analisando-se o número de lesões por centímetro e por folha, notou-se com maior clareza as diferenças existentes entre as variedades, inclusive possibilitando a obtenção de uma classificação muito semelhante àquela obtida para o isolado H.O. 82-1 (Tabela 2).

Uma provável explicação para isso, seria o fato de que isolados menos agressivos não consigam promover uma pressão de seleção suficiente para a detecção de 
diferenças quanto à resistência à colonização. Por outro lado, a resistência à infecção atuou de forma semelhante tanto para o isolado agressivo, como para o isolado com agressividade baixa, resultando em reações semelhantes quando se inoculou uma determinada variedade com um tipo ou outro de isolado.

Tabela 3. Reações de variedades de arroz inoculadas com suspensão de conídios do isolado H 22 em casa de vegetação.

\begin{tabular}{|c|c|c|c|c|c|}
\hline Variedade & $\begin{array}{l}\text { Tipo } \\
\text { lesão }\end{array}$ & Nota ${ }^{(1)}$ & No/cm & No/follha & Área $\left(\mathrm{mm}^{2}\right)$ \\
\hline Labelle & $\mathrm{A}$ & 2 & $3,16 \mathrm{a}^{(2)}$ & $100,50 \mathrm{a}$ & $0,34 a b$ \\
\hline IR-5 & $\mathrm{A}$ & 1 & $3,10 \mathrm{a}$ & $74,16 \mathrm{abc}$ & $0,25 \mathrm{~b}$ \\
\hline CICA-8 & $\mathrm{A}$ & 2 & $3,05 \mathrm{a}$ & $67,00 \mathrm{abcd}$ & $0,40 \mathrm{ab}$ \\
\hline Lebonet & $\mathrm{A}$ & 2 & $2,83 \mathrm{ab}$ & $86,83 a b$ & $0,36 a b$ \\
\hline IAC-201 & A & 2 & $2,60 \mathrm{abc}$ & $80,50 \mathrm{ab}$ & $0,50 a b$ \\
\hline Carreon & A & 2 & $2,60 \mathrm{abc}$ & $87,00 \mathrm{ab}$ & $0,45 a b$ \\
\hline Colômbia-1 & A & 2 & $2,16 \mathrm{abcd}$ & 59,33 abcd & $0,34 a b$ \\
\hline Taichung & A & 2 & $1,88 \mathrm{abcd}$ & $60,66 \mathrm{abcd}$ & $0,30 a b$ \\
\hline Dawn & $\mathrm{A}$ & 2 & $1,59 \mathrm{abcd}$ & 47,16 bcd & $0,31 \mathrm{ab}$ \\
\hline IR-8 & $\mathrm{A}$ & 2 & $1,33 \mathrm{bcd}$ & 38,00 bcd & $0,50 \mathrm{ab}$ \\
\hline Dular & A & 2 & $1,33 \mathrm{bcd}$ & $52,83 \mathrm{abcd}$ & $0,56 a b$ \\
\hline Metica-1 & A & 2 & $1,05 \mathrm{~cd}$ & $29,66 \mathrm{~cd}$ & $0,33 \mathrm{ab}$ \\
\hline Ag. B. Torto & A & 2 & $1,04 \mathrm{~cd}$ & 38,66 bcd & $0,58 a b$ \\
\hline IV-29-4 & A & 2 & 0,86 & $27,16 \mathrm{~cd}$ & $1,04 \mathrm{a}$ \\
\hline Caloro & A & 2 & 0,76 & 23,00 & $0,55 \mathrm{ab}$ \\
\hline Awini & A & 1 & 0,65 & 19,33 & $0,25 \quad b$ \\
\hline
\end{tabular}

Média de 10 repetições. $\mathrm{CV}=27,5 \%$

(1) Com base na escala de Aluko.

(2) Médias seguidas por letras distintas, nas colunas, diferem entre si pelo teste de Tukey ao nível de 5\% de probabilidade.

Pode-se dizer também que, não sendo o micélio uma estrutura adaptada à infecção, não foi possível estabelecer diferenças entre as variedades inoculadas com 
suspensão de micélio de H.O. 82-1, quando se considerou os parâmetros que medem a frequência de infecção (Tabela 4).

Tabela 4. Reações de variedades de arroz inoculadas com suspensão de micélio do isolado H.O. 82-1 em casa de vegetação.

\begin{tabular}{|c|c|c|c|c|c|c|}
\hline Variedade & $\begin{array}{l}\text { Tipo } \\
\text { lesão }\end{array}$ & Nota $^{(1)}$ & No/cm & №/folha & Área & $\left(\mathrm{mm}^{2}\right)$ \\
\hline IV-29-4 & $\mathrm{C}$ & 4 & $0,84 a^{(2)}$ & $28,66 \mathrm{ab}$ & $4,22 \mathrm{a}$ & \\
\hline Caloro & $\mathrm{C}$ & 4 & $0,60 \mathrm{a}$ & $22,83 a b$ & 3,18 & $\mathrm{~b}$ \\
\hline Colômbia-1 & $\mathrm{C}$ & 4 & $2,10 \mathrm{a}$ & $56,00 \mathrm{ab}$ & 2,43 & bc \\
\hline Carreon & B & 3 & $1,49 \mathrm{a}$ & $50,33 \mathrm{ab}$ & 1,87 & $\mathrm{~cd}$ \\
\hline Ag. B. Torto & B & 3 & $0,66 \mathrm{a}$ & $22,83 \mathrm{ab}$ & 1,48 & de \\
\hline IAC-201 & B & 3 & $1,71 \mathrm{a}$ & $55,16 \mathrm{ab}$ & 1,31 & de \\
\hline Lebonet & B & 3 & $2,10 \mathrm{a}$ & $68,16 \mathrm{a}$ & 1,29 & $\operatorname{def}$ \\
\hline Labelle & A & 2 & $1,77 \mathrm{a}$ & $59,33 a b$ & 1,01 & efg \\
\hline Dawn & A & 2 & $1,51 \mathrm{a}$ & $41,66 \mathrm{ab}$ & 0,55 & fgh \\
\hline CICA-8 & A & 2 & $0,66 \mathrm{a}$ & $15,16 \mathrm{~b}$ & 0,47 & gh \\
\hline IR-8 & A & 2 & $0,78 \mathrm{a}$ & $19,33 \mathrm{ab}$ & 0,40 & gh \\
\hline Taichung & A & 2 & $1,02 \mathrm{a}$ & $29,16 \mathrm{ab}$ & 0,40 & gh \\
\hline Dular & A & 2 & $1,03 \mathrm{a}$ & $36,33 \mathrm{ab}$ & 0,38 & gh \\
\hline Metica-1 & A & 2 & $1,67 \mathrm{a}$ & $51,16 \mathrm{ab}$ & 0,37 & $\mathrm{gh}$ \\
\hline Awini & A & 1 & $0,70 \mathrm{a}$ & $23,83 \mathrm{ab}$ & 0,29 & gh \\
\hline IR-5 & A & 1 & $1,27 \mathrm{a}$ & $36,50 \mathrm{ab}$ & 0,25 & $\mathrm{~h}$ \\
\hline
\end{tabular}

Média de 10 repetições. CV $=37,3 \%$

(1) Com base na escala de Aluko

(2) Médias seguidas por letras distintas, nas colunas, diferem entre si pelo tesre de Tukey ao nível de 5\% de probabilidade.

Nos casos em que a infecção pelo micélio foi bem sucedida, a resistência à colonização permitiu agrupar as variedades em resistentes, intermediárias e suscetíveis, de maneira semelhante àquela obtida quando se inoculou suspensão de conídios deste mesmo isolado. 
Quando foi inoculada suspensão de micélio do isolado $\mathrm{H} 22$, não ocorreu aparecimento de lesões em nenhuma das variedades. Confirmou-se, portanto, a baixa capacidade do micélio em causar infecção e também o menor grau de patogenicidade deste isolado.

Estes resultados mostraram que a avaliação da reação de uma variedade não deve ser feita considerando-se somente um dos parâmetros, uma vez que há mais de um tipo de resistência envolvida. Seria interessante, portanto, que a avaliação fosse feita através da combinação de diferentes parâmetros, de tal forma que fosse possível revelar, para cada variedade, tanto a resistência à infecção como a resistência à colonização.

A tabela 5 mostra que os resultados da inoculação com suspensão de conídios foram sempre superiores aos obtidos com suspensão de micélio quanto aos parâmetros número de lesões por centímetro, número de lesões por folha e área das lesões.

Tabela 5. Reações de variedades de arroz inoculadas com suspensões de conídios e de micélio do isolado H.O. 82-1 em casa de vegetação.

Parâmetro(1)

Suspensão de conídios

Suspensão de micélio

№ lesões/cm

$2,99 a^{(2)}$

$1,24 \mathrm{~b}$

№ lesões/folha

$93,20 \mathrm{a}$

$38,53 \mathrm{~b}$

Área lesões $\left(\mathrm{mm}^{2}\right)$

1,95 a

$1,24 \mathrm{~b}$

(1) Média de 16 variedades. $C V=26,3 \%$

(2) Médias seguidas por letras distintas, nas linhas, diferem entre si pelo teste de Tukey ao nível de 5\% de probabilidade.

Esses resultados, de certa forma estão de acordo com aqueles relatados por SHERF et al. (1947) e por GANGULY \& PADMANABHAN (1959), que encontraram 
semelhanças entre as lesões produzidas por conídios e micélio de $H$. oryzae. No entanto, quando se utilizou fragmentos de micélio, o número de infecções foi muito reduzido.

Portanto, pode-se afirmar que a utilização de uma suspensão de micélio não foi o método mais adequado para se avaliar a reação de variedades de arroz à $H$. oryzae em casa de vegetação. A pressão de seleção é baixa, pois o micélio não apresentou boa capacidade de infecção.

\subsection{Ensaio conduzido com folhas destacadas em placas de Petri.}

Neste ensaio, todos os parâmetros avaliados permitiram classificar as variedades quanto à reação das mesmas ao patógeno (Tabela 6).

No $3^{\circ}$ dia após a inculação das folhas, não foi possivel observar diferenças marcantes entre os diferentes métodos de inoculação, enquanto que no $7^{\circ}$ dia uma grande parte das folhas já estavam amareladas e também prejudicaram este tipo de observação. Dessa forma, os resultados obtidos no $5^{2}$ dia após a inoculação foram aqueles que melhor evidenciaram as reações dos diferentes materiais de arroz e, portanto, propiciaram avaliar mais seguramente o efeito dos métodos de inoculação.

Observou-se uma certa correlação entre os parâmetros tipo de lesão, nota e área das lesões, mas não entre estes e o número de lesões por segmento. Como já foi discutido anteriormente, isso ocorre porque os primeiros parâmetros refletem a reação das variedades em relação à colonização, enquanto o número de lesões por folha se relaciona à infecção.

Com relação à inoculação através de suspensão de conídios do isolado H 22 (Tabela 7), os resultados confirmaram o que já havia ocorrido em casa de vegetação, ou seja, devido à baixa patogenicidade do isolado não foi possível detectar diferenças quanto à resistência das variedades em relação à colonização. Foi observado que todas as 
variedades testadas se comportaram como resistentes quanto ao tipo de lesão, nota e área das lesões. Entretanto, as diferenças na resistência à infecção puderam ser detectadas através do número de lesões por folha.

Tabela 6. Reações de variedades de arroz inoculadas com suspensão de conídios do isolado H.O. 82-1 em placas de Petri.

\begin{tabular}{|c|c|c|c|c|}
\hline Variedade & $\begin{array}{l}\text { Tipo } \\
\text { lesão }\end{array}$ & Nota ${ }^{(1)}$ & №/segmento & Área $\left(\mathrm{mm}^{2}\right)$ \\
\hline Colômbia-1 & $\mathrm{B}$ & 3 & $143,23 \mathrm{a}^{(2)}$ & $1,92 \mathrm{ab}$ \\
\hline Lebonet & B & 3 & $141,38 \mathrm{a}$ & $1,55 \mathrm{c}$ \\
\hline IAC-201 & B & 3 & $133,67 \mathrm{ab}$ & $1,70 \mathrm{bc}$ \\
\hline CICA-8 & A & 2 & $133,90 \mathrm{ab}$ & $0,75 \quad \mathrm{e}$ \\
\hline Taichung & B & 3 & $127,14 \mathrm{abc}$ & $1,18 \quad d$ \\
\hline Dular & B & 3 & $123,86 \mathrm{abcd}$ & $1,77 \mathrm{abc}$ \\
\hline Carreon & A & 2 & $113,11 \mathrm{bcd}$ & 0,36 \\
\hline Metica-1 & A & 2 & $112,60 \mathrm{bcd}$ & 0,56 \\
\hline Awini & A & 2 & $111,71 \mathrm{bcd}$ & 0,53 \\
\hline IR-8 & A & 2 & $105,90 \mathrm{~cd}$ & 0,58 \\
\hline Labelle & A & 2 & $103,90 \mathrm{de}$ & 0,52 \\
\hline IR-5 & A & 2 & 82,09 & 0,66 ef \\
\hline Caloro & B & 3 & 81,95 & $1,86 a b c$ \\
\hline Ag. B. Torto & B & 3 & 69,05 & $1,53 \mathrm{~cd}$ \\
\hline Dawn & B & 3 & 60,67 & $1,85 \mathrm{abc}$ \\
\hline IV-29-4 & B & 3 & 53,62 & $2,11 \mathrm{a}$ \\
\hline
\end{tabular}

Média de 10 repetições. $C V=14,7 \%$

(1) Com base na escala de Aluko.

(2) Médias seguidas de letras distintas, nas colunas, diferem entre si pelo teste de Tukey ao nível de $5 \%$ de probabilidade. 
Tabela 7. Reações de variedades de arroz inoculadas com suspensão de conídios do isolado $\mathrm{H} 22$ em placas de Petri.

\begin{tabular}{|c|c|c|c|c|c|}
\hline Variedade & $\begin{array}{l}\text { Tipo } \\
\text { lesão }\end{array}$ & $\operatorname{Nota}^{(1)}$ & №\%/segm & iento & Área $\left(\mathrm{mm}^{2}\right)$ \\
\hline Lebonet & $\mathrm{A}$ & 2 & $153,43 a$ & & $0,38 \mathrm{bc}$ \\
\hline Colômbia-1 & A & 2 & $135,50 \mathrm{a}$ & & $0,85 \mathrm{a}$ \\
\hline CICA-8 & $\mathrm{A}$ & 1 & 122,01 & bc & $0,25 \mathrm{c}$ \\
\hline Dular & A & 2 & 116,69 & bed & $0,61 \mathrm{ab}$ \\
\hline IAC-201 & A & 2 & 106,05 & cde & $0,46 \mathrm{bc}$ \\
\hline Awini & A & 1 & 98,65 & def & $0,25 \mathrm{c}$ \\
\hline Carreon & $\mathrm{A}$ & 1 & 88,40 & efg & $0,25 \mathrm{c}$ \\
\hline IR-8 & A & 1 & 87,46 & efg & $0,25 \mathrm{c}$ \\
\hline Metica-1 & $\mathrm{A}$ & 1 & 87,22 & efg & $0,25 \mathrm{c}$ \\
\hline IR-5 & $\mathrm{A}$ & 1 & 79,52 & fgh & $0,25 \mathrm{c}$ \\
\hline Taichung & A & 2 & 79,23 & fgh & 0,35 bc \\
\hline Labelle & A & 1 & 77,88 & fgh & $0,25 \quad \mathrm{c}$ \\
\hline Caloro & A & 2 & 77,19 & fgh & 0,48 bc \\
\hline Dawn & A & 2 & 74,86 & gh & 0,32 bc \\
\hline Ag. B. Torto & A & 2 & 74,16 & gh & $0,55 \mathrm{abc}$ \\
\hline IV-29-4 & A & 2 & 59,92 & $\mathrm{~h}$ & $0,55 \mathrm{abc}$ \\
\hline
\end{tabular}

(1) De acordo com a escala de Aluko.

(2) Médias seguidas por letras distintas, nas colunas, não diferem entre si pelo teste de Tukey ao nivel de $5 \%$ de probabilidade.

Comparando-se as variedades em relação ao parâmetro número de lesões por folha para os dois isolados testados (Tabelas 6 e 7), constatou-se muitas semelhanças quanto às reações ao patógeno. Assim, as variedades Colômbia, Lebonet, Awini, Carreon, IR-8, Metica, Dawn, Agulha Bico Torto e IV-29-4 mantiveram a mesma reação frente a ambos os isolados. As demais variedades, com exceção da Taichung, apresentaram uma variação pequena. 
Os resultados das inoculações com micélio também se assemelharam aos resultados obtidos em casa de vegetação quanto aos parâmetros avaliados. Micélio do isolado H 22 mais uma vez não foi capaz de causar infecção em nenhuma das variedades. Quanto à suspensão de micélio do H.O. 82-1, ficou evidenciado pelos dados da Tabela 8 que é possível se classificar as variedades com base no tipo de lesão, nota e área da lesão.

Tabela 8. Reações de variedades de arroz inoculadas com suspensão de micélio do isolado H.O. 82-1 em placas de Petri.

\begin{tabular}{|c|c|c|c|c|}
\hline Variedade & $\begin{array}{l}\text { Tipo } \\
\text { lesão }\end{array}$ & $\operatorname{Nota}^{(1)}$ & No/segmento & Área $\left(\mathrm{mm}^{2}\right)$ \\
\hline Caloro & B & 3 & $13,90 \mathrm{a}$ & $1,68 \mathrm{~b}$ \\
\hline CICA-8 & A & 2 & $18,30 \mathrm{a}$ & $0,68 \quad d$ \\
\hline Lebonet & B & 3 & $17,20 \mathrm{a}$ & 1,47 bc \\
\hline IAC-201 & B & 3 & $16,10 \mathrm{a}$ & $1,18 \quad \mathrm{c}$ \\
\hline Awini & A & 2 & $15,80 \mathrm{a}$ & 0,46 \\
\hline Taichung & $\mathrm{A}$ & 2 & $15,90 \mathrm{a}$ & 0,58 \\
\hline Metica & A & 2 & $15,90 \mathrm{a}$ & $0,42 \quad d$ \\
\hline Dular & B & 3 & $15,60 \mathrm{a}$ & $1,57 \quad b$ \\
\hline Colômbia & B & 3 & $13,70 \mathrm{a}$ & $2,13 \mathrm{a}$ \\
\hline IR-8 & $\mathrm{A}$ & 2 & $13,40 \mathrm{a}$ & 0,43 \\
\hline IR-5 & $\mathrm{A}$ & 2 & $13,20 \mathrm{a}$ & 0,43 \\
\hline Labelle & A & 2 & $12,90 \mathrm{a}$ & 0,52 \\
\hline Carreon & $\mathrm{A}$ & 2 & $11,30 \mathrm{a}$ & 0,55 \\
\hline Ag. B. Torto & $\mathrm{A}$ & 2 & $10,20 \mathrm{a}$ & $0,60 \quad \mathrm{~d}$ \\
\hline IV-29-4 & B & 3 & $7,90 \mathrm{a}$ & $1,72 \mathrm{~b}$ \\
\hline Dawn & A & 2 & $7,50 \mathrm{a}$ & 0,42 \\
\hline
\end{tabular}

Média de 10 repetições. $\mathrm{CV}=28,1 \%$

(1) De acordo com a escala de Aluko.

(2) Médias seguidas por letras distintas, nas colunas, não diferem entre si pelo teste de Tukey ao nível de $5 \%$ de probabilidade. 
Todas as variedades se revelaram como resistentes quando se empregou suspensão de micélio, pois apresentaram um pequeno número de lesões por folha. Isso confirmou, mais uma vez, a baixa capacidade infectiva do micélio, não permitindo que se estabelecesse diferenças entre as variedades para alguns parâmetros avaliados.

O tipo de lesão e a nota relativa às variedades foram praticamente idênticos quando se empregou suspensão de conídios ou de micélio do isolado H.O. 82-1. São exceções as variedades Taichung, Agulha Bico Torto e Dawn, que se mostraram mais resistentes em placas de Petri.

A inoculação de folhas através de discos de micélios conduzida em placas de Petri foi realizada de maneira mais fácil quando comparada com a inoculação de plantas mantidas em casa de vegetação. $\mathrm{O}$ isolado $\mathrm{H} 22$ não provocou o aparecimento de lesões, porém o isolado H.O.82-1 causou lesões de diferentes tamanhos dependendo da variedade considerada, permitindo agrupá-las em resistentes, intermediárias e suscetiveis (Tabela 9).A classificação das reações varietais, obtida através deste método, não mostrou nenhuma relação com aquela apresentada pela área das lesões produzidas por conídios deste isolado (Tabela 6).

Considerando-se que a classificação das variedades a partir da área das lesões produzidas por conídios representa melhor as condições naturais, pode-se afirmar que a inoculação com discos de micélio foi inadequada para determinar a reação varietal. Ainda, a inoculação com suspensão de conídios se mostrou mais conveniente quando comparada com a suspensão de micélio (Tabela 10), permitindo melhor visualização das diferenças entre as variedades, considerando-se todos os parâmetros avaliados.Ficou evidente, mais uma vez, que inoculações com micélio não foram adequadas para avaliar a reação de variedades de arroz devido à baixa pressão de seleção apresentada por esse tipo de inóculo. 
Tabela 9 Área das lesões em 16 variedades de arroz inoculadas através de discos de micélio do isolado H.O. 82-1 em placas de Petri.

\begin{tabular}{|c|c|}
\hline Variedade & Área $\left(\mathrm{cm}^{2}\right)$ \\
\hline $\mathbb{I R}-5$ & $0,80 a^{(1)}$ \\
\hline Metica-1 & $0,79 \mathrm{a}$ \\
\hline Taichung & $0,66 \mathrm{ab}$ \\
\hline Colômbia-1 & $0,65 \mathrm{ab}$ \\
\hline Lebonet & $0,50 \mathrm{bc}$ \\
\hline IV-29-4 & $0,45 \mathrm{~cd}$ \\
\hline Carreon & $0,44 \mathrm{~cd}$ \\
\hline Dawn & 0,41 cde \\
\hline Dular & 0,39 cdef \\
\hline Caloro & 0,39 cdef \\
\hline CICA-8 & 0,32 \\
\hline IAC-201 & 0,32 \\
\hline Awini & 0,31 \\
\hline IR-8 & 0,27 \\
\hline Ag. B. Torto & 0,26 \\
\hline Labelle & 0,24 \\
\hline
\end{tabular}

(1) Médias seguidas por letras distintas, na coluna, diferem entre si pelo teste de Tukey ao nível de $5 \%$ de probabilidade.

Tabela 10. Reações de variedades de arroz inoculadas com suspensões de conídios e de micélio do isolado H.O. 82-1 em placas de Petri.

\begin{tabular}{lcc}
\hline Parâmetro ${ }^{(1)}$ & Suspensão de conídios & Suspensão de micélio \\
\hline & & \\
& $116,11 \mathrm{a}^{(2)}$ & $13,67 \mathrm{~b}$ \\
& & \\
Área lesões $\left(\mathrm{mm}^{2}\right)$ & $1,21 \mathrm{a}$ & $0,93 \mathrm{~b}$ \\
\hline
\end{tabular}

(1) Média de 16 variedades. $C V=17,3 \%$

(2) Médias seguidas por letras distintas, nas linhas, diferem entre si pelo teste de Tukey ao nível de 5\% de probabilidade. 


\subsection{Ensaio conduzido em câmara de crescimento.}

Os resultados mostraram que é praticamente inviável separar as variedades testadas em grupos distintos, quanto ao grau de resistência ou de suscetibilidade. As dimensões das lesões exibidas pelas diferentes variedades são relativamente pequenas, não permitindo a caracterização de tipos definidos de lesão, nem a distinção das lesões com base no tamanho das mesmas. Esperava-se que a partir dos discos de micélio colocados sobre as folhas se desenvolvessem lesões com expansão diferenciada em função da variedade considerada. No entanto, apesar do aparecimento de pequenas manchas, não houve um crescimento suficiente que tornasse possível caracterizar estas lesões. Mesmo sob o disco de micélio as lesões foram irregulares, normalmente puntiformes, algumas vezes coalescidas. Apesar da desuniformidade das lesões, ainda foi possível a determinação da área das mesmas, porém os resultados finais não foram satisfatórios. Assim, a inoculação por discos de micélio mais uma vez se confirmou como um método inadequado para a avaliação da reação de variedades.

\subsection{Ensaio conduzido no campo.}

As constantes inoculações com $H$. oryzae acabaram provocando uma epidemia de mancha parda no campo, que interferiu nos resultados das inoculações. Todos os tratamentos, inclusive as testemunhas inoculadas com água, apresentaram alta severidade de doença, não permitindo que se observassem diferenças entre as formas de inóculo. Apenas as variedades IV-29-4, Lebonet, IAC-201 e Labelle puderam ser avaliadas. Essas variedades atingiram a maturação e foram retiradas do campo antes que a epidemia interferisse de maneira significativa na reação das plantas. Os resultados deste ensaio estão apresentados na Tabela 11. 
Tabela 11 Índice de doença em panículas de 4 variedades de arroz inoculadas por injeção de suspensões de inóculo no campo.

\begin{tabular}{|c|c|c|c|c|c|}
\hline \multirow[t]{2}{*}{ Variedades } & \multicolumn{5}{|c|}{ Suspensões de inóculo(1) } \\
\hline & S.C. 82-1 & S.M. 82-1 & S.C. 22 & S.M. 22 & ÁGUA \\
\hline IV-29-4 & $3,10 a^{(2)}$ & $2,00 \mathrm{a}$ & $1,82 \mathrm{a}$ & $1,40 \mathrm{a}$ & $1,46 \mathrm{a}$ \\
\hline Lebonet & $2,70 \mathrm{~b}$ & $1,49 \mathrm{~b}$ & $1,65 \mathrm{ab}$ & $1,37 \mathrm{a}$ & $1,39 \mathrm{a}$ \\
\hline IAC-201 & $2,57 \mathrm{~b}$ & $1,38 \mathrm{~b}$ & $1,48 \mathrm{~b}$ & $1,41 \mathrm{a}$ & $1,39 \mathrm{a}$ \\
\hline Labelle & $1,60 \mathrm{c}$ & $1,34 \quad b$ & $1,43 \mathrm{~b}$ & $1,37 \mathrm{a}$ & $1,48 \mathrm{a}$ \\
\hline Médias & $2,49 \mathrm{~A}$ & $1,55 \mathrm{~B}$ & $1,59 \mathrm{~B}$ & $1,38 \mathrm{C}$ & $1,43 \mathrm{C}$ \\
\hline
\end{tabular}

Média de 15 repetições. $\mathrm{CV}=14,0 \%$

(1) S.C. = Suspensão de Conídios; S.M. = Suspensão de Micélio

(2) Médias seguidas por letras minúsculas distintas, nas colunas, e por letras maiúsculas distintas, na linha,diferem entre si pelo teste de Tukey ao nível de $5 \%$ de probabilidade.

A análise dos resultados da Tabela 11 indicou que a inoculação com suspensão de conídios do isolado H.O. 82-1 foi a que permitiu detectar variação quanto à reação das variedades. Dessa forma foi possível classificar como suscetível a variedade IV-29-4, como intermediárias Lebonet e IAC-201 e como resistente Labelle. Para as outras formas de inóculo, inclusive para a suspensão de conídios do isolado $\mathrm{H} 22$, essa distinção não foi tão nítida. Esses resultados indicaram que, numa inoculação para caracterização da resistência à mancha parda nas panículas, deve-se considerar dois aspectos : o inóculo deve ser representado por conídios e o isolado deve apresentar patogenicidade alta. $\mathrm{O}$ uso de micélio ou de isolados com baixa patogenicidade pode não exercer uma pressão de seleção adequada para que se evidenciem as diferenças entre as variedades.

Quando se avaliou a porcentagem de perda de peso dos grãos (Tabela 12), os resultados reforçaram essa hipótese. Percebe-se que as diferenças entre as variedades foram mais acentuadas quando se utilizou a suspensão de conídios do isolado H.O. 82-1, levando a uma classificação idêntica àquela obtida para o índice de doença. Assim, a 
variedade IV-29-4 manteve seu comportamento suscetível, apresentando 35,4\% de perda de peso, enquanto que a Labelle não diferiu da testemunha quando foi inoculada com suspensão de conídios do isolado H.O. 82-1.

Tabela 12 Porcentagem de perda de peso dos grãos, em relação à testemunha inoculada com água, para 4 variedades de arroz inoculadas através de injeção de suspensões de inóculo no campo.

\begin{tabular}{|c|c|c|c|c|}
\hline \multirow[t]{2}{*}{ Variedades } & \multicolumn{4}{|c|}{ Suspensões de inóculo ${ }^{(1)}$} \\
\hline & S.C. 82-1 & S.M. 82-1 & S.C. 22 & S.M. 22 \\
\hline IV $-29-4$ & $35,40 \mathrm{a}^{(2)}$ & $7,20 \mathrm{ab}$ & $11,50 \mathrm{a}$ & $16,00 \mathrm{a}$ \\
\hline Lebonet & $22,40 \mathrm{~b}$ & $1,30 \mathrm{ab}$ & $1,00 \mathrm{ab}$ & $0,80 \mathrm{~b}$ \\
\hline IAC-201 & $16,20 \mathrm{~b}$ & $13,00 \mathrm{a}$ & $12,00 \mathrm{a}$ & $4,00 \mathrm{~b}$ \\
\hline Labelle & $-2,20 \quad c$ & $-0,70 \quad b$ & $0,00 \quad b$ & $0,00 \mathrm{~b}$ \\
\hline Médias & $17,90 \mathrm{~A}$ & $5,20 \mathrm{~B}$ & $6,10 \mathrm{~B}$ & $5,20 \mathrm{~B}$ \\
\hline
\end{tabular}

Média de 5 repetições. CV $=20,2 \%$

(1) S.C. $=$ Suspensão de Conídios; S.M. = Suspensão de Micélio

(2) Médias seguidas por letras minúsculas distintas, nas colunas, e por letras maiúsculas distintas, na linha,diferem entre si pelo teste de Tukey ao nível de $5 \%$ de probabilidade.

Nas condições deste ensaio, observou-se que quanto maior a área manchada dos grãos, maior a perda de peso apresentada pelos mesmos. Dessa forma, a maioria dos grãos que receberam nota 4 (mais que $50 \%$ do grão manchado) se mostravam completamente "chochos", confirmando os relatos de PRABHU \& BEDENDO (1982a).

FAZLI \& SCHROEDER (1966a) já haviam relatado perdas significativas na produção de grãos da variedade Bluebonet quando realizaram inoculações artificiais nas panículas, sendo que os maiores danos foram obtidos quando as inoculações foram feitas na fase de floração. No Brasil, PRABHU et al. (1980) encontraram reduções de até 30 \% na produção em condições de campo, com variedades de sequeiro. Essa redução esteve associada principalmente com infecções de $H$. oryzae nos grãos. 


\subsection{Relação entre os ensaios.}

Comparando-se os resultados obtidos em casa de vegetação com aqueles do ensaio com folhas destacadas, observa-se que esse último confirma os resultados do primeiro no que se refere à relação entre os tipos de inóculo e os parâmetros avaliados. Em ambos os experimentos ficou evidenciado que a suspensão de conídios do isolado mais patogênico (H.O. 82-1) representou a forma mais adequada de inoculação, permitindo que se avaliasse tanto a resistência à infecção quanto a resistência à colonização em todas as variedades. Outra evidência revelada nesses experimentos foi a superioridade da suspensão de conídios em relação à de micélio para todos os parâmetros avaliados, superioridade esta traduzida pela possibilidade de detecção de diferenças entre as variedades com resistência ou suscetibilidade. Com isto, foi possivel classificá-las em grupos de materiais resistentes, intermediários e suscetíveis. Sob um aspecto mais amplo, confrontando-se os resultados obtidos nestes ensaios, não se observou correlação positiva entre as reações das variedades, havendo casos em que a mesma variedade se apresentou como resistente num experimento e suscetível no outro.

Quanto ao experimento em câmara de crescimento, os resultados não permitiram definir de maneira clara as reações varietais. Estes resultados não apresentaram relação alguma com os resultados obtidos em outros ensaios. Confirmou-se, portanto, que esse método não foi adequado para avaliar a reação das variedades.

Considerando-se os resultados mais expressivos do ensaio no campo, ou seja, aqueles obtidos com suspensão de conídios do isolado H.O. 82-1, observou-se relação destes com aqueles obtidos para as mesmas variedades em casa de vegetação, mais especificamente com os parâmetros que medem a resistência à colonização (Tabela 13). 
Tabela 13. Reações de 4 variedades de arroz inoculadas com suspensão de conídios do isolado H.O. 82-1 em casa de vegetação e no campo.

\begin{tabular}{|c|c|c|c|c|c|}
\hline \multirow{2}{*}{$\begin{array}{l}\text { Variedade } \\
\text { s }\end{array}$} & \multicolumn{3}{|c|}{ Casa de Vegetação } & \multicolumn{2}{|c|}{ Campo } \\
\hline & Tipo lesão & Nota $^{(1)}$ & Área & $I \mathrm{D}^{(2)}$ & \% Perda \\
\hline IV-29-4 & $S^{(3)}$ & $S$ & $S$ & $S$ & $S$ \\
\hline Lebonet & I & I & I & I & I \\
\hline IAC-201 & I & I & I & I & I \\
\hline Labelle & $\mathbf{R}$ & $\mathbf{R}$ & I & $\mathbf{R}$ & $\mathbf{R}$ \\
\hline
\end{tabular}

(1) Com base na escala de Aluko

(2) Índice de Doença.

(3) $\mathrm{S}=$ Suscetível; I = Intermediária; $\mathrm{R}=$ Resistente.

Assim, a variedade IV-29-4, considerada suscetivel segundo os parâmetros avaliados em casa de vegetação, manteve o mesmo comportamento quando se avaliou a reação dos grãos à mancha parda no campo. 0 mesmo ocorreu com as variedades Lebonet e IAC-201, consideradas intermediárias em ambos os ensaios. A variedade Labelle, que se apresentou como resistente segundo os resultados do campo, foi considerada como intermediária com base no parâmetro área das lesões, medido em casa de vegetação. Apesar dessa variedade ter apresentado lesões relativamente grandes, classificando-se como intermediária, tais lesões não possuíam centro nécrotico definido, caracterizando reação resistente quando se considerou os parâmetros tipo de lesão e nota segundo a escala de Aluko.

Isso sugere a possibilidade de se realizar testes de avaliação de variedades em plantas com 30 dias, com base na reação foliar. No entanto, é necessário que o inóculo seja constituído por conídios de um isolado com patogenicidade alta e que o parâmetro avaliado indique a resistência à colonização. 
Resultados semelhantes a estes já haviam sido relatados por Ou \& Nuque ${ }^{1}$, citados por OU (1985) para o sistema Oryza sativa x Pyricularia oryzae. Injetando suspensões de conídios de diversos isolados de $P$. oryzae nas panículas emergentes, esses autores constataram que as variedades que tinham reação foliar resistente não apresentaram brusone de pescoço. Por outro lado, as variedades com reação foliar suscetível apresentaram incidências de 46 a $100 \%$ de brusone de pescoço, indicando haver correlação positiva entre a resistência à brusone nas folhas e no pescoço.

${ }^{1}$ OU, S.H. \& NUKE, F.L. The relation between leaf and neck resistance to the rice blast disease. International Rice Commission Newsletter, 12(4), 30-5, 1963. 


\section{CONCLUSÕES}

Com base nos resultados obtidos, pode-se concluir que:

a) A patogenicidade do isolado de $H$. oryzae mostrou ter influência na reação da variedade, devendo ser levada em consideração quando se busca determinar a resistência ou suscetibilidade de materiais de arroz.

b) A inoculação com conídios de isolados com alto grau de patogenicidade foi o melhor método para detectar diferenças nas reações entre variedades.

c) As inoculações com micélio, tanto na forma de discos de ágar como na forma de suspensão, não foram adequadas para caracterizar reações varietais em plantas de arroz.

d) $\mathrm{O}$ uso de folhas destacadas não se mostrou adequado para a avaliação das variedades de arroz por não apresentar relação com os resultados obtidos no campo.

e) As reações das variedades no campo apresentaram boa correlação com as reações de resistência ou suscetibilidade à colonização mostradas por plantas com 30 dias em casa de vegetação. 


\section{REFERÊNCIAS BIBLIOGRÁFICAS}

ALUKO, M.O. The measurement of brown leaf spot on rice. PANS. Pest Articles and News Summaries, London, 16(1) : 76-81, mar.1970.

ARTIGIANI FO, V.H. \& BEDENDO, I.P. Gramíneas de importância econômica como possíveis hospedeiros alternativos para Helminthosporium oryzae. In: CONGRESSO PAULISTA DE FITOPATOLOGIA, 17., Araras, 1994. Resumos. Summa Phytopathologica, Jaguariúna, 20(1) : 46, jan./mar. 1994.

ASHOUR, W.A.; SIRRY, A.R.; ABDEL-HAK, T.M.; KAMEL, S.M. Effect of environmental factors on blast and brown spot diseases of rice in A.R.E. Agricultural Research Review, Cairo, 51 : 29-44, may 1973.

BEDENDO, I.P. \& KRÜGNER, T.L. Fungitoxicidade de benomyl e chlorothalonil a Cylindrocladium pteridis e sua persistência após pulverizações em folhas de Eucalyptus cloeziana. Fitopatologia Brasileira, Brasília, 12(3) : 236-9, set. 1987.

BEDENDO, I.P. \& PRABHU, A.S. Epifitotias de Helminthosporium oryzae em arroz em condições de casa de vegetação. In: CONGRESSO BRASILEIRO DE FITOPATOLOGIA, 12., Ilhéus, 1979. Resumos. Fitopatologia Brasileira, Brasília, 1(4) : 93, fev. 1979.

BEDENDO,I.P. \& PRABHU, A.S. Um método de avaliação de germoplasma de arroz para resistência à mancha parda nos grãos. In: CONGRESSO BRASILEIRO DE FITOPATOLOGIA, 15., São Paulo, 1982. Resumos. Fitopatologia Brasileira, Brasília, 7(3) : 512, out. 1982. 
BEDI, K.S. \& GILL, H.S. Losses caused by the brown leaf-spot of rice in the Punjab. Indian Phytopathology, New Delhi, 13 : 161 - 4, 1960.

BRIGNANI NETO, F.; LASCA, C.C.; AMARAL, R.EM.; LEITE, Y.R.; OLIVEIRA, D.A. Tratamento de sementes de arroz com fungicidas visando diminuir a disseminação de patógenos. In : REUNIÃO DE TÉCNICOS EM RIZICULTURA DO ESTADO DE SÃO PAULO, 1., Campinas. Anais. Campinas, CATI, 1979. p. 125-31.

BRIGNANI NETO, F.; LEITE, N.; AMARAL, R.E.M.; ROLIM, P.R.R.; OLIVEIRA, D.A. Efeito de pulverizações com fungicidas sobre a helmintosporiose do arroz. $\mathbf{O}$ Biológico, São Paulo, 48(2) : 33 - 8, fev. 1982.

BROERS, L.H.M. \& LOPEZ-ATILANO, R.M. A method of inoculating adult wheat plants with urediospores of Puccinia striiformis to measure components of resistance. Plant Disease, St. Paul, 78(4) : 353 - 7, abr. 1994.

FANTIN, G.M.; MALAVOLTA, V.M.A.; KIMATI, H. Teste de fungicidas "in vitro"e "in vivo" para o controle de Bipolaris oryzae, agente causal da mancha parda do arroz. In: CONGRESSO PAULISTA DE FITOPATOLOGIA, 17., Araras, 1994. Resumos. Summa Phytopathologica, Jagariúna, 20(1) : 43, jan./mar. 1994.

FARIA, J.C. \& PRABHU, A.S. A screening technique to evaluate resistance of rice to Rhynchosporium oryzae. Plant Disease, St. Paul, 64(9) : 845 - 6, set. 1980.

FAZLI, S.F.I. \& SCHROEDER, H.W. Effect of kernel infection of rice by Helminthosporium oryzae on yield and quality. Phytopathology, St. Paul, 56(9) : 1003 - 5, sept. 1966a.

FAZLI, S.F.I. \& SCHROEDER, H.W. Kernel infection of bluebonet 50 rice by Helminhosporium oryzae. Phytopathology, St. Paul, 56(5) : 507 - 9, may 1966b. 
GANGULY, D. \& PADMANABHAN, S.Y. Helminthosporium disease of rice III. Breeding resistant varieties - Selection of resistant varieties from genetic stock. Indian Phytopathology, New Delhi, 12 : 99 - 110, 1959.

GUIMARÃES, E.P.; MORAIS, O.P.; BARROS, L.G.; NEIVA, L.C.S.; SOARES, A.A.; BAZONI, R.; PRABHU, A.S.; PINHEIRO, B.S. Desenvolvimento, avaliação e lançamento da cultivar precoce guarani para o arroz de sequeiro. Pesquisa Agropecuária Brasileira, Brasília, 24(8) : 969 - 74, ago. 1989.

ISLA, L.H. Resistência varietal del arroz a Helminthosporium oryzae. Centro Agricola, Santa Clara, 5(2):47-55, may/ago. 1978.

ISSA, E.; AMARAL, R.E.M.; SOUZA, D.M.;BANZATO, N.V. Resistência varietal do arroz à brusone, à mancha parda e à mulata. O Biológico, São Paulo, 39 : 321 - 35, 1973.

LAKSHMANAN, P. \& VELUSAMY, R. Resistance to sheat blight (ShB) and brown spot (BS) in lines derived from Oryza officinalis. International Rice Research Newsletter, Manila, 16(6) : 8 - 9, dec. 1991.

MALAVOLTA, V.M.A.; SOUZA, T.M.W.; AMARAL, R.E.M. Avaliação de reações foliares de cultivares/linhagens de arroz à mancha parda (Bipolaris oryzae). Summa Phytopathologica, Jaguariúna, 18(2) : 118 - 24, abr./jun. 1992.

MENDES, B.M.J. \& BERGAMIN FILHO, A. Adaptação da técnica da cultura de folha destacada para a quantificação de parâmetros epidemiológicos monocíclicos da ferrugem do feijoeiro (Uromyces phaseoly var. typica). Fitopatologia Brasileira, Brasília, 11 : 103 - 14, mar. 1986.

MORAES, S.A. \& SALGADO, C.L. Utilização da técnica de folhas destacadas de amendoim (Arachis Hipogaea L.) para inoculações com Cercospora Arachidicola Hori e Cercospora Personata (Berk. \& Curt.) Ell. \& Ev. Summa Phytopathologica, Jaguariúna, 8 : 39 - 55, jul./dez. 1982. 
NELSON, R.R. \& KLINE, D.N. The pathogenicity of certain species of Helminthosporium to species of the gramineae. Plant Disease Reporter, Beltsville, 45(8) : 644 - 8, Aug. 1961.

OU, S.H. Brown Spot. In: ------. Rice Diseases. 2.ed. Farhan Royal, Commonwealth Mycological Institute, 1985. p. 201 - 22.

PADMANABHAN, S.Y.; GANGULY, D.D.; BALAKRISHNAN, M.S. Helminthosporium disease of rice II. Source and development of seedling infection. Indian phytopathology, New Delhi, 6 : 96 - 105, 1953.

PADMANABHAN, S.Y.; GANGULY, D.D.; CHANDWANI, G.H. Helminthosporium disease of rice VIII. Breeding resistant varieties : Selection of resistant varieties of early duration from genetic stock. Indian Phytopathology, New Delhi, 19 : 72 -5, 1965.

PADMANABHAN, S.Y.; ROY CHOUDHRY, K.R.; GANGULY, D.D. Helminthosporium disease of rice I. Nature and extent of damage caused by the disease. Indian Phytopathology, New Delhi, 1(1) : 34 - 47, 1948.

POPE, D.D. \& McCARTER, S.M. Evaluation of inoculation methods for inducing common smut on corn ears. Phytopathology, St. Paul, 82 (9) : 950 - 5, 1992.

PRABHU, A.S. \& BEDENDO, I.P. Principais doenças do arroz no Brasil. Goiânia, EMBRAPA/CNPAF, 1982a. 31 p. (EMBRAPA/CNPAF. Documentos, 2).

PRABHU, A.S. \& BEDENDO, I.P. Reações de diversos gêneros e espécies de gramíneas à infecção por Rhynchosporim oryzae. Pesquisa Agropecuária Brasileira, Brasília, 17(5) : 703 - 8, mai. 1982b.

PRABHU, A.S. \& BEDENDO, I.P. Avaliação de germoplasma de arroz para resistência a Gerlachia oryzae. Pesquisa Agropecuária Brasileira, Brasília, 25(8) : 1093 100, ago. 1990. 
PRABHU, A.S.; LOPES, A.M.; SALIMOS, S.P. Avaliação de resistência horizontal à mancha parda em arroz. In: REUNIÃO NACIONAL DE PESQUISA DE ARROZ, 2., Goiânia, 1980. Resumos. Brasília, EMBRAPA/CNPAF, 1986. p.300 - 1.

PRABHU, A.S.; LOPES, A.M.; ZIMMERMANN, F.J.P. Infecção da folha e do grão de arroz por Helminthosporium oryzae e seus efeitos sobre os componentes de produção. Pesquisa Agropecuária Brasileira, Brasília, 15(2) : 183 - 9, abr. 1980.

RIBEIRO, A.S. Teste de resistência à mancha parda (Helminthosporium oryzae) em cultivares de arroz irrigado. In: REUNIÃO DA CULTURA DO ARROZ, 7., Porto Alegre, 1977. Anais. Pelotas, IRGA/UEPAE, 1977. p.123 - 4.

SANTOS, J.R.M. \& GALVÃO, E.U.P. Avaliação de doenças em germoplasma de arroz em várzea e em terra firme no Amazonas. Pesquisa Agropecuária Brasileira, Brasília, 24(12) : 1483 - 8, dez. 1989.

SHERF, A.F.; PAGE, R.M.; TULLIS, E.C.; MORGAN, T.L. Studies on factors affecting the infectivity of Helminthosporium oryzae. Phytopathology, St. Paul, 37 : $281-90,1947$.

SINGH, R.A. \& SHARMA, V.V. Evaluation of rice germplasms and varieties for resistence to brown spot. Il Riso, Milano, 24(4) : 382 - 6, 1975.

SINGH, R.N. Evaluation of indigenous rice varieties for resistance to brown spot. Indian Phytopathology, New Delhi, 41(4) : 635 - 7, 1988.

SOAVE, J.; PIZZINATO, M.A.; USBERTI JR., J.A.; CAMARGO, O.B.A.; VILLELA, O.V. Selection of rice cultivars resistant to some pathogens using seed health testing. Pesquisa Agropecuária Brasileira, Brasília, 19(4) : 449 - 54, abr. 1984.

SOUSA, N.R.G.; RIBEIRO, A.S.; GALLI, J. Identificação de fontes de resistência à mancha parda em arroz irrigado. Pesquisa Agropecuária Brasileira, Brasília, 21(4) : 393 - 7, abr. 1986. 
SRIVASTAVA, M.P. \& MAHESHWARI S.K. Varietal resistance of rice to brown leaf spot. III Riso, Milano, $20: 271$ - 3, 1971.

VALARINI, P.J.; LASCA, C.C.; CHIBA, S. Eficiência de fungicidas em tratamento de sementes de arroz para controle de Helminthosporium oryzae. Pesquisa Agropecuária Brasileira, Brasília, 2(1) : 41 - 4, jan. 1988.

WARD, C.H. The detached - leaf technique for testing alfafa clones for resistance to black stem. Phytopathology, St. Paul, 49(10) : 690 - 5, oct. 1959.

WILCOXSON, R.D.; ATIF, A.H.; SKOVMAND, B. Slow rusting of wheat varieties in the field correlated with stem rust severity on detached leaves in the greenhouse. Plant Disease Reporter, Beltsville, 58(12) : 1085 - 7, dec. 1974.

YARWOOD, C.E. Detached leaf culture. The Botanical Review, Bronx, 12(1) : 1 56, 1956. 